\title{
Research on Social Capital Selection of Public-Private-Partnership Project
}

\author{
Yufang Shi, Pingping Song \\ School of Management, Xi'an University of Science and Technology, Xi'an, China \\ Email:2045321756@qq.com, 39597495@qq.com
}

How to cite this paper: Shi, Y.F. and Song, P.P. (2018) Research on Social Capital Selection of Public-Private-Partnership Project. Open Access Library Journal, 5: e4652.

https://doi.org/10.4236/oalib.1104652

Received: May 10, 2018

Accepted: June 3, 2018

Published: June 6, 2018

Copyright $\odot 2018$ by authors and Open Access Library Inc.

This work is licensed under the Creative Commons Attribution International License (CC BY 4.0).

http://creativecommons.org/licenses/by/4.0/

\section{c) (i) Open Access}

\begin{abstract}
The way of cooperation between government and social capital is widely used in the field of infrastructure construction. According to relevant data, the social capital participating in PPP (Public Private Partnership) project is divided into three categories, and the strengths and weaknesses are analyzed; the evaluation index system of social capital is constructed from four aspects of financial ability, technical ability, management ability and historical project evaluation, and the selection evaluation model is constructed based on fuzzy comprehensive evaluation method; finally, taking a wastewater treatment plant PPP project as an example, the model is proved to be scientific and reasonable, and provides a new way for the government to choose social capital.
\end{abstract}

\section{Subject Areas}

Civil Engineering

\section{Keywords}

Public Private Partnership Project, Social Capital Selection, Fuzzy

Comprehensive Evaluation

\section{Introduction}

Public Private Partnership (PPP) originated in Britain in 1980s. Generalized PPP refers to the form of government and social capital cooperation for the provision of public products or services. The main forms of the generalized PPP are BOT, BOO, BOOT, TOT, MC, etc. The narrow sense PPP refers to the establishment of the government and social capital on the basis of complementary advantages, risk sharing and sharing of interests. By signing a contract, the PPP item company is formed together to provide a long-term partnership of public service. The introduction of social capital in the field of infrastructure construction by 
PPP projects, to a great extent, relieves the financial pressure of the government and improves the efficiency of the supply of public services; in addition, revitalizes the stock capital of the society and raises the turnover rate of a large number of idle capitals in the society [1]. As the leader of the PPP project, the government selects suitable social capital as one of the key factors for the success of the PPP project. In practice, the government's choice of social capital is relatively single, and the composition of the selection index is not entirely suitable for specific PPP project types. Therefore, for different types of PPP projects, how to choose to evaluate social capital indicators and determine whether it is suitable social capital is the most important problem faced by relevant government departments.

In recent years, foreign scholars have tried to evaluate social capital in the PPP project, and have tried fuzzy comprehensive scoring, fuzzy analytic hierarchy process, data envelopment method and other [2] [3] [4]. Most of the domestic scholars focus on the risk identification and sharing of PPP projects, bidding process and evaluation methods etc. There are few studies on the evaluation of social capital. On the basis of the research of relevant experts, Wu Haoying [5] calculates the weights of each index by using analytic hierarchy process (AHP), and makes a general arrangement for each evaluation index. It provides a theoretical support for selecting the appropriate private sector as a partner for the PPP project at the county level. From the overall perspective, Liu Hong [6] uses the Analytic Network Process (ANP) to analyze the capabilities of social capital investors in terms of finance, technology, management, and cooperation and build a fuzzy comprehensive evaluation model to select the best social capital. Ren Zhitao [7] selected the indicators for evaluation of the private sector through the method of frequency analysis of literature, constructed the index system of the system and adopted the method of gray correlation analysis to study the selection of the private sector of the PPP project. On the basis of previous research, this paper uses AHP to analyze and calculate the weight of social capital index, and constructs the selection evaluation model based on fuzzy comprehensive evaluation method, in order to determine whether the selected social capital is optimal.

\section{Social Capital Types of PPP Projects and Comparative Analysis}

Based on the national bid data of PPP, this paper divides the social capital of China's PPP projects into three categories: construction contractors, financial institutions (investment institutions) and operators. Most construction contractors have rich engineering construction experience and strong project management capabilities, but they lack experience in PPP project implementation. It is not very good at critical operation management of PPP project, and the general construction contractor is also difficult to cope with the large capital demand of the PPP project. As a financial institution (investment institution) whose social capital directly participates in PPP projects, it has a wide range of financing 
channels and strong financial strength. It can meet the funding needs of each stage of project design, construction, operation and maintenance. However, because of the talent structure and other constraints, financial institutions (investments institutions) do not yet have the engineering project integrated management capabilities. Operators' participation in PPP projects can improve project operation efficiency to a certain extent, but since the PPP project basically with a long construction cycle and relatively large cost, it is difficult to raise enough construction and operation funds by the power of the operator only in the short term. The advantages and disadvantages of these three types of social capital are shown in Table 1.

In reality, in key areas such as municipal infrastructure and social public utilities, due to the long construction period, large capital requirements, and difficult controllability of risks, a single social capital cannot resist the risk of the whole life cycle of the project. So, we often select joint capital to give full play to the respective advantages of social capital and achieve the optimal allocation of resources.

\section{Construction of Evaluation Index System for Social Capital Selection of PPP Project}

\subsection{Principles of PPP Project Social Capital Selection Evaluation Index}

Compared with traditional engineering projects, the large amount of capital required for PPP projects and the long construction and operation period require social capital to have rigid conditions such as rich project experience, advanced technical strength, strong financial support, and excellent management capabilities; On the other hand, any PPP project has a certain public welfare or quasi-public welfare, It requires the social capital side to have certain social conditions of responsibility, business reputation and other flexible conditions.

Therefore, the selection of social capital evaluation indicators by the government should be different from the selection of bid selection indicators by the traditional engineering project owners. It is necessary to follow certain principles in accordance with the actual conditions of PPP projects. This article is based on the previous research [8] and believed that the selection of social capital evaluation indicators should follow the following principles.

1) According to the final goal of the project, choose the index that can best make up for the project but lack its own;

Table 1. Various types of social capital advantages and disadvantages.

\begin{tabular}{lll}
\hline \multicolumn{1}{c}{ Types } & \multicolumn{1}{c}{ Advantages } & \multicolumn{1}{c}{ Disadvantages } \\
\hline construction contractors & $\begin{array}{l}\text { strong project management } \\
\text { capabilities }\end{array}$ & poor capital strength \\
$\begin{array}{l}\text { financial institutions (investment } \\
\text { institutions) }\end{array}$ & $\begin{array}{l}\text { extensive financing channels } \\
\text { strong financial strength }\end{array}$ & $\begin{array}{l}\text { poor integration of project } \\
\text { management }\end{array}$ \\
operators & strong operational ability & poor resource integration \\
\hline
\end{tabular}


2) Choose indicators that are representative, suitable in number, and have certain differences;

3) Indicators should be scientific, practical, and operational.

\subsection{Analysis of Influencing Factors of PPP Projects Social Capital Selection}

1) Financial Capability

The financial capability reflects the investment and financing capabilities of social capital, its own financial status and financial risk control capabilities. In China, PPP projects are mainly concentrated on municipal facilities such as water supply and power supply, urban rail transit facilities such as highways and railways, and public service projects such as medical treatment and tourism, and water conservancy, resource and environment projects. For urban rail transit projects, the construction cost per kilometer is as high as 1 billion yuan, and the construction period of water supply, power supply, and medical facilities is generally relatively long. Therefore, it is difficult for social capital parties to be competent if there is not enough capital resources. To this end, this paper presents four indicators of financial strength, credit status, financing strength, financial risk control ability to measure the financial capacity of social capital.

The financial strength reflects the self-owned capital of PPP project social capital that can be used for this PPP project; The credit status shows the capital turnover of social capital and the stability of the capital supply chain; The financing strength is reflected in the ability of social capital to raise funds. The return rate of PPP projects is low and the cost of traditional financing channels is high. The low return rate of the PPP project can hardly completely cover the cost of a single financing channel, so social capital must have strong financing strength; The construction period of the PPP project is long, and the implementation process is easily influenced by the financial factors such as the state exchange rate, which requires the strong financial risk control ability of the social capital.

2) Technical Capability

Technical capability is one of the key factors to ensure the smooth construction and operation of PPP projects. Evaluation of technical capabilities will touch many factors, and the technical elements involved in different projects are not completely the same. In this paper, the construction technology level, qualification level, technical core equipment, rationality of operation and maintenance plans, and five indicators of construction plans are selected for comprehensive assessment.

The construction technology level is the primary condition for the selection of social capital, and the higher construction technology level is the guarantee for the smooth completion of the PPP project; The qualification level indicates that the project scope and project scale of social capital are the minimum requirements for social capital; Infrastructure projects generally require large scale and complex construction processes, which require relatively high technical equip- 
ment; Operation and maintenance programs can reflect whether the services provided by social capital during the operation period can meet the project requirements; The construction plan is a specific implementation plan for the project; A scientific and rational construction plan can effectively reduce the construction cost, shorten the construction period, and increase the construction efficiency.

3) Management Capability

Management capability is the embodiment of social capital's management level in terms of schedule, quality, cost, construction period, operation and maintenance involved in the whole life cycle of the project. Through consultation with experts in related fields, we identified five indicators: project management capabilities, project operation and maintenance capabilities, risk response capabilities, resource integration capabilities, and business scale to measure social capital management capabilities.

Project management capability refers to the ability of managers to meet their expectations on schedule or ahead of schedule under limited resource conditions. The project has injected a certain cost into the operation period, and the good operation and maintenance ability can improve the profit rate of the project. The PPP project has more risk factors and more complex degree in the construction process, and demands the social capital party has a strong ability to deal with risk. The resource integration capability is the ability of social capital to effectively organize and coordinate PPP projects for all parties involved in orderly project construction and the large scale enterprises often have a more complete organization and management system, which can ensure the efficient completion of the project.

4) Historical Project Evaluation

Historical project evaluation is the feedback of the quality of the project or the owner's social reputation and cooperation ability of social capital. Theoretically, the higher the quality of social capital, the higher the quality and efficiency of project completion, and the better the public services provided to the society. Through reading the literature, the author lists five evaluation indexes related to historical project evaluation: social influence, similar project owner satisfaction, similar project construction experience, contract performance rate, and professional service ability.

Social influence refers to the reputation of social capital and also reflects the adverse events of the social capital side. The degree of owner satisfaction of similar projects refers to the evaluation made by the parties involved with the social capital and the cooperation ability of the social capital. In general, the more experienced the construction of similar projects, the higher the quality of project construction. The higher contract fulfillment rate indicates that the completion of social capital projects is better. The professional service ability in the whole life cycle of the project is the speed of the social capital to solve all kinds of problems in the construction period and the operation period. 


\subsection{Construction of Evaluation Index System for Social Capital Selection of PPP Projects}

Based on the above analysis of the evaluation indicators for social capital selection of PPP projects, this paper constructs an evaluation index system composed of four first-level indicators and nineteen second-level indicators, as shown in Table 2. For the sake of simplification, B1, B2, B3 and B4 are substituted for financial ability, technical ability, management ability and historical project evaluation in the following sections.

\section{PPP project Social Capital Selection Based on Fuzzy Comprehensive Evaluation}

\subsection{Fuzzy Comprehensive Evaluation Procedure}

The fuzzy comprehensive evaluation method was founded by Professor Zade, an American scientist in the 1960s. It was originally an evaluation method designed for a large number of economic phenomena with ambiguity in reality. This method is suitable for subjective qualitative description of some ambiguous phenomena that are difficult to quantify, thus closely combining qualitative description with quantitative analysis [9]. In general, fuzzy comprehensive evaluation has the following steps:

Table 2. PPP project social capital selection evaluation index system.

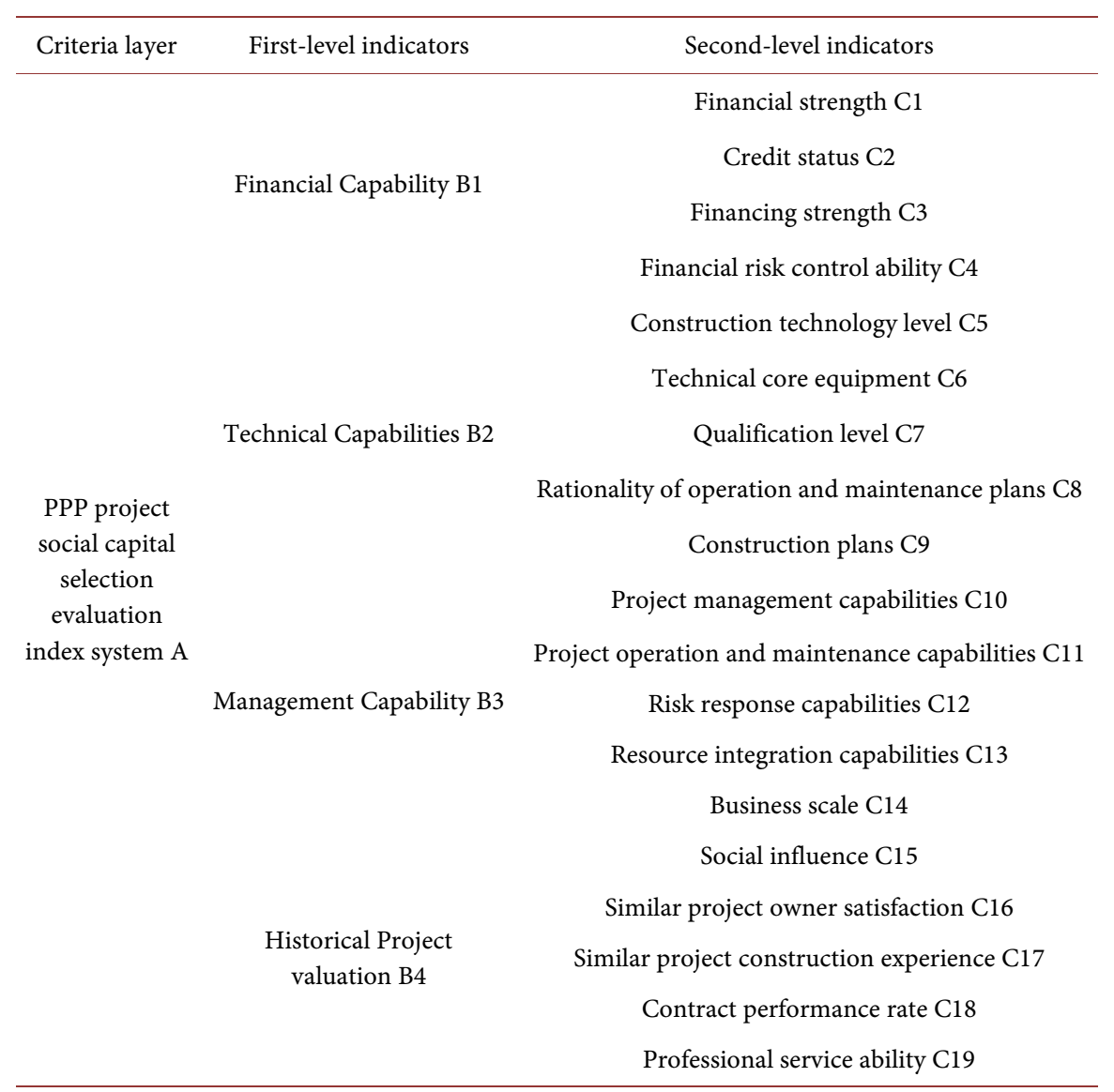


1) Establish an evaluation factor set $U=\left\{u_{1}, u_{2}, \cdots, u_{n}\right\}$

The evaluation factor is the reflection of various characteristics or attributes of the evaluation object, is the parameter of the evaluation object, and is also a comprehensive reflection of the quality of the evaluation object. The ambiguity of the evaluation factor is the basis for the fuzzy evaluation.

2) Set up a comment set $V=\left\{v_{1}, v_{2}, \cdots, v_{i}\right\}$

The comment set is a set of comprehensive evaluation results made by the evaluator on the evaluation object and is generally represented by five levels of excellent, good, medium, poor, and bad.

3) Determine the single factor assessment membership degree vector to form the membership degree matrix

According to the attribute characteristics of factor set and comment set, the membership of each element is found out, and membership functions and membership degrees are calculated. The degree of membership refers to the possibility that a number of evaluation subjects make a $v_{j}$ assessment for a certain object in $u_{i}$, and the membership degree vector of the evaluation factor $R_{i}=\left\{r_{i 1}, r_{i 2}, \cdots, r_{i n}\right\}$, and single factor fuzzy evaluation matrix $R$ is the set of all single factor fuzzy evaluation membership vectors.

In the fuzzy comprehensive evaluation, there are many types of function to determine the relation of membership degree, which are commonly used as sine function, parabolic function, exponential function and linear function. The linear membership function is constructed based on the number of experts $C$.

The number of experts with $C$ is set, and $C_{k}$ is the number of experts belonging to the $k$ level for $x_{i} \cdot r_{i k}$ is the membership degree of $x_{i}$ belonging to the grade $V_{i}$ and the fuzzy membership function of $x_{i}$ is as follows.

$$
r_{i k}=\left\{\begin{array}{l}
0, \text { There are zero people who think } x_{i} \text { belongs to grade } v_{i} \\
\frac{c_{k}}{c}, \text { There are } c_{k} \text { people who think } x_{i} \text { belongs to grade } v_{i}
\end{array}\right.
$$

4) Establishment of factor weight set $W=\left\{w_{1}, w_{2}, \cdots, w_{n}\right\}$

The analytic hierarchy process (AHP) is used to give each factor a certain weight according to the importance of the factors and the set of weights of each factor becomes the factor weight set.

5) Fuzzy comprehensive evaluation

The fuzzy comprehensive analysis of the indicators of each layer is performed separately, and the result of fuzzy comprehensive evaluation is that the single factor fuzzy evaluation matrix and the corresponding set of weights perform fuzzy calculation results, as Equation (2).

$$
B=W * R=\left\{w_{1}, w_{2}, \cdots, w_{n}\right\} *\left[\begin{array}{cccc}
r_{11} & r_{12} & \cdots & r_{1 m} \\
r_{21} & r_{22} & \cdots & r_{2 m} \\
\vdots & \vdots & \ddots & \vdots \\
r_{n 1} & r_{n 2} & \cdots & r_{n m}
\end{array}\right]
$$

6) Calculate the overall score of the evaluation object

The comprehensive evaluation result $B$ is transformed into the comprehensive 
score $Z$, and then sorted according to the $Z$ value of the comprehensive score. The highest score is the result of social capital selection.

$$
Z=B * V^{\mathrm{T}}=\left\{B_{1}, B_{2}, \cdots, B_{n}\right\} *\left[\begin{array}{c}
v_{1} \\
v_{2} \\
\vdots \\
v_{n}
\end{array}\right]
$$

\subsection{Evaluation Standards of Social Capital}

In order to better reflect the specific conditions of social capital, after the quantification of social capital evaluation indicators, evaluation criteria should be established. Here, with reference to the results of a general comprehensive evaluation, five levels of excellence, good, middle, poor, and bad are used to indicate whether social capital is suitable for the project (Table 3).

\section{Empirical Analysis}

China is currently in the exploration phase of the PPP project. There are fewer projects in the operational phase of the PPP project library. This paper selects a PPP project of a wastewater treatment plant to verify the scientificity and operability of the model.

\subsection{Case Background}

The PPP project of a sewage treatment plant is a newly built project, which includes sewage treatment plants, sewage interception pipes and 4 pumping stations along the line. The government and social capital jointly set up the item company to finance, build, operate and maintain the project and transfer the project to the government after the expiration of the 17 year concession period.

The initial investment of the project is 988 million RMB. The government adopts public tendering to select social capital. After the comparison and screening at the project preparation stage, the consortium's social capital A and the single social capital B and C finally participate in the final bidding phase. The Consortium Social Capital A consists of an investment company and an integrated water company. The company B is a comprehensive water company that invests in the development and supply of urban water supply and wastewater projects in the country, as well as the construction and operation of environmental

Table 3. Social capital evaluation standards.

\begin{tabular}{ccc}
\hline Level & Score & Suit or not \\
\hline Excellence & 8 (inclusive)-10 points & Suitable \\
Good & 6 (inclusive) -8 points & Suitable \\
Middle & 4 (inclusive)-6 points & Suitable \\
Poor & 2 (inclusive)- 4 points & Unsuited \\
Bad & Less than 2 points & Unsuited \\
\hline
\end{tabular}


protection and municipal infrastructure. The company $\mathrm{C}$ is an investment company and its parent company is the world's top 500 .

\subsection{Fuzzy Evaluation of Social Capital Selection}

\subsubsection{Determining Indicator Weights}

By consulting experts and scholars who are engaged in PPP project related work and research fields, and quoting Satty's 1-9 scale method, the first-level index judgment matrix is shown in Table 4 , and the weight of each index factor is calculated.

CR $<0.10$ shows that the judgment matrix has acceptable consistency. This determines the weight of the first-level indicators of the social capital evaluation system for PPP projects, that is, the importance of B1, B2, B3, and B4 for A, $W=\{0.444,0.235,0.235,0.0769\}$. Similarly, the index weights of CB1 are $\{0.353,0.111,0.353,0.182\}$, the index weights of CB2 are $\{0.1750 .056,0.331,0.331,0.108\}$, the index weights of $\mathrm{CB} 3$ are $\{0.325,0.325,0.106,0.172,0.072\}$, the index weights of $\mathrm{CB} 4$ are $\{0.067,0.252,0.452,0.148,0.081\}$. Among them, CRB1 $=0.00407, \mathrm{CRB} 2=$ $0.0163, \mathrm{CRB} 3=0.00984, \mathrm{CRB} 4=0.0252$ all meet the consistency standard

\subsubsection{Determining the Degree of Membership Matrix}

Now we employ 10 senior workers in PPP project and professors in PPP related fields in Colleges and universities, and conduct fuzzy comprehensive evaluation on each factor set according to the evaluation set.

For the consortium social capital $A$, a fuzzy evaluation matrix $R_{i}$ is established according to formula (1).

$$
\begin{gathered}
R_{1}=\left[\begin{array}{ccccc}
0.8 & 0.2 & 0 & 0 & 0 \\
0.6 & 0.3 & 0.1 & 0 & 0 \\
0.7 & 0.3 & 0 & 0 & 0 \\
0.4 & 0.3 & 0.3 & 0 & 0
\end{array}\right], R_{2}=\left[\begin{array}{ccccc}
0.7 & 0.2 & 0.1 & 0 & 0 \\
0.5 & 0.3 & 0.2 & 0 & 0 \\
0.6 & 0.4 & 0 & 0 & 0 \\
0.6 & 0.2 & 0.2 & 0 & 0 \\
0.6 & 0.3 & 0.1 & 0 & 0
\end{array}\right] \\
R_{3}=\left[\begin{array}{ccccc}
0.8 & 0.2 & 0 & 0 & 0 \\
0.4 & 0.3 & 0.2 & 0.1 & 0 \\
0.5 & 0.4 & 0.1 & 0 & 0 \\
0.5 & 0.2 & 0.2 & 0.1 & 0 \\
0.6 & 0.3 & 0.1 & 0 & 0
\end{array}\right], R_{4}=\left[\begin{array}{ccccc}
0.4 & 0.3 & 0.2 & 0.1 & 0 \\
0.6 & 0.2 & 0.1 & 0.1 & 0 \\
0.7 & 0.2 & 0.1 & 0 & 0 \\
0.6 & 0.3 & 0.1 & 0 & 0 \\
0.3 & 0.2 & 0.2 & 0.2 & 0.1
\end{array}\right]
\end{gathered}
$$

First, according to the formula (2), the fuzzy evaluation of the two-level index is carried out, and the fuzzy membership vector $B_{i}$, which is about the financial capability, the technical ability, the management ability and the historical project evaluation, is obtained.

$$
\begin{gathered}
B_{1}=\left\{\begin{array}{lllll}
0.353 & 0.3 & 0.182 & 0 & 0
\end{array}\right\}, B_{2}=\left\{\begin{array}{lllllll}
0.331 & 0.331 & 0.2 & 0 & 0
\end{array}\right\} \\
B_{3}=\left\{\begin{array}{lllllll}
0.325 & 0.3 & 0.2 & 0.1 & 0
\end{array}\right\}, B_{4}=\left\{\begin{array}{llllll}
0.452 & 0.2 & 0.1 & 0.1 & 0.081
\end{array}\right\}
\end{gathered}
$$

Similarly, the fuzzy membership vector of social capital $B$ and social capital $C$ can be obtained. 
Table 4. First-level index evaluation matrix.

\begin{tabular}{ccccc}
\hline A & $\begin{array}{c}\text { Financial } \\
\text { Capability B1 }\end{array}$ & $\begin{array}{c}\text { Technical } \\
\text { Capabilities B2 }\end{array}$ & $\begin{array}{c}\text { Management } \\
\text { Capability B3 }\end{array}$ & $\begin{array}{c}\text { Historical Project } \\
\text { Evaluation B4 }\end{array}$ \\
\hline Financial Capability B1 & 1 & 2 & 2 & 4 \\
Technical Capabilities B2 & $1 / 2$ & 1 & 1 & 4 \\
$\begin{array}{c}\text { Management Capability B3 } \\
\text { Historical Project }\end{array}$ & $1 / 2$ & 1 & 1 & 4 \\
Evaluation B4 & $1 / 4$ & $1 / 4$ & $1 / 4$ & 1 \\
\hline
\end{tabular}

$\lambda \max =4.074, \mathrm{CI}=0.023, \mathrm{CR}=0.026<0.1$.

The degree of membership of social capital B:

$$
\begin{aligned}
B_{1}=\left\{\begin{array}{lllll}
0 & 0.353 & 0.3 & 0.353 & 0.1
\end{array}\right\}, B_{2}=\left\{\begin{array}{llllll}
0.331 & 0.3 & 0.175 & 0.175 & 0
\end{array}\right\} \\
B_{3}=\left\{\begin{array}{llllllll}
0.3 & 0.325 & 0.325 & 0.2 & 0.1
\end{array}\right\}, B_{4}=\left\{\begin{array}{llllll}
0.452 & 0.252 & 0.252 & 0.081 & 0
\end{array}\right\}
\end{aligned}
$$

The degree of membership of social capital C:

$$
\begin{gathered}
B_{1}=\left\{\begin{array}{lllll}
0.353 & 0.2 & 0 & 0 & 0
\end{array}\right\}, B_{2}=\left\{\begin{array}{lllllll}
0.056 & 0.108 & 0.331 & 0.331 & 0.2
\end{array}\right\} \\
B_{3}=\left\{\begin{array}{llllllll}
0 & 0.072 & 0.325 & 0.325 & 0.2
\end{array}\right\}, B_{4}=\left\{\begin{array}{llllll}
0.252 & 0.3 & 0.1 & 0.452 & 0.1
\end{array}\right\}
\end{gathered}
$$

\subsubsection{Fuzzy Comprehensive Evaluation}

Based on the evaluation results of the indicator layer, the first-level indicators are evaluated. The results are:

$$
\begin{aligned}
B^{*} & =W * B \\
& =\{0.444,0.235,0.235,0.0769\} *\left[\begin{array}{ccccc}
0.353 & 0.3 & 0.182 & 0 & 0 \\
0.331 & 0.331 & 0.2 & 0 & 0 \\
0.325 & 0.3 & 0.2 & 0.1 & 0 \\
0.452 & 0.2 & 0.1 & 0.1 & 0.081
\end{array}\right] \\
& =\{0.346,0.297,0.182,0.0312,0.00623\}
\end{aligned}
$$

Normalization: $B^{*}=\{0.401,0.344,0.211,0.0362,0.00722\}$

According to the foregoing, the project evaluation results are divided into five grades of $v_{1}$ (excellent), $v_{2}$ (good), $v_{3}$ (middle), $v_{4}$ (poor) and $v_{5}$ (bad), and correspond to the corresponding values: $V=\left(v_{1}, v_{2}, v_{3}, v_{4}, v_{5}\right)=(10,8,6,4,2)$, then the comprehensive score of the project is:

$$
Z=B * V^{\mathrm{T}}=\{0.401,0.344,0.211,0.0362,0.00722\} *\left[\begin{array}{c}
10 \\
8 \\
6 \\
4 \\
2
\end{array}\right]=8.187
$$

Similarly, the social capital $B$ has a $Z$ value of 6.567 , and the social capital $C$ has a $Z$ value of 6.557 , so that the collective social capital $A$ is selected. In practice, the project also chose the social capital $A$ of the consortium. The fuzzy evaluation result is consistent with the actual situation, which verifies the scientificity of the model. 


\section{Conclusion}

This paper uses AHP and fuzzy comprehensive evaluation method to evaluate and select social capital. Through reading PPP literature data, it classifies social capital according to related data and analyzes its advantages and disadvantages. This paper constructs a social capital evaluation index system, sets up the evaluation index set and the membership degree vector and gives the evaluation standard of social capital. Finally, the scientificity of the model is verified by the PPP project of a sewage treatment plant, which provides a new method for government departments to choose social capital.

\section{Acknowledgements}

The authors would like thank the PPP project expert for completing the questionnaire.

\section{References}

[1] Zhou, L.P. (2016) PPP Project Operations. Law Press, Beijing.

[2] Zhang, X.Q. (2009) Best Value Concessionaire Selection through a Fuzzy Logic System. Expert Systems with Applications, 36, 227-254. https://doi.org/10.1016/j.eswa.2008.09.039

[3] Wu, Q. and Gao, Y.N. (2012) Selection Model of Concessionaire in PPP Projects. Applied Mechanics and Materials, 180, 108-130. https://doi.org/10.4028/www.scientific.net/AMM.174-177.2906

[4] El-Mashaleh, M.S. and Edward, R.M. (2013) Concessionaire Selection Model Based on Data Envelopment Analysis. Journal of Management in Engineering, 131, 484-494.

[5] Wu, H.Y. (2016) Research on Private Sector Evaluation Method of County-Level Urban PPP Project Based on AHP. Project Management Technology, 42-47.

[6] Liu, H. (2016) PPP Project Social Capital Selection Based on Fuzzy Network Analysis. Finance and Accounting Monthly, 32, 50-54.

[7] Ren, Z.T. (2016) The Selection Model of Private Sector of PPP Project Based on Grey Relational Degree. Journal of Tianjin University of Urban Construction, 12, 444-449.

[8] Zhao, Y. (2013) Research on the Choice of Franchise Operator of BOT Project. Dongbei University of Finance and Economics, Dalian, 9-55.

[9] Wang, X.P. (2011) Management System Engineering: Methodology and Modeling. Mechanical Industry Press, Beijing. 